\title{
Memorial Funerário Mathias Haas:

\author{
a trajetória da criação de um espaço sobre \\ a morte e os cemitérios
}

\author{
Funeral Memorial Mathias Haas: the trajectory of \\ creating a space on death and cemeteries
}

\section{RESUMO}

O artigo descreve a trajetória do Memorial Funerário Mathias Haas localizado em Blumenau, Santa Catarina, abordando as etapas de sua formação, desde o início de seu projeto de criação, em 2010, até os dias atuais. O Memorial é o primeiro museu sobre o tema da morte e dos cemitérios do Brasil, e abrigará o acervo reunido pela família Haas, desde 0 início do século $\mathrm{XX}$. $\mathrm{O}$ arquivo preservado pela família está relacionado com a trajetória de sua empresa, e é formado por artigos de funerária, ornamentos tumulares, fotografias, registros de empregados, desenhos, materiais de expediente, dentre outros. $O$ acervo já está sendo inventariado e se destaca por sua diversidade, sendo atualmente um dos maiores acervos preservados sobre uma empresa do ramo.

Palavras-chave: Museus - Patrimônio Cultural Funerário - História Morte - Cemitérios

\begin{abstract}
The article describes the Mathias Haas Funeral Memorial's trajectory located in Blumenau, Santa Catarina, comprising the development stages, from the beginning of its creation project in 2010 to the present day. The Memorial is the first museum about the subject of death and graveyards in Brazil and will house the collection gathered by the Haas family since the beginning of the 20th century. The archive preserved by the family are related to the company's trajectory and is formed by funeral articles, tombstone ornaments, photographs, employee's records, drawings, working materials, among others. The collection is already being inventoried and stands out due the diversity and is currently one of the largest collections preserved on a funerary company.
\end{abstract}

Keywords: Museums - Funerary Cultural Heritage - History - Death Cemeteries

* Doutora em História Cultural pela Universidade Federal de Santa Catarina (UFSC), Brasil. Presidente da Associação Brasileira de Estudos Cemiteriais (ABEC). CV: http://lattes.cnpq. $\underline{\mathrm{br} / 0954333963638792}$ 


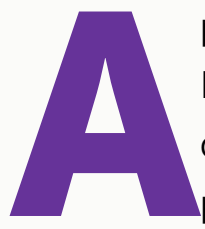

proposta de compartilhar a experiência da criação do Memorial Funerário Mathias Haas para a sessão Em campo da Revista M. tornou-se um agradável exercício de recordar bons e criativos momentos, diante da expectativa de abertura de sua primeira exposição e inauguração, em julho de 2017.

A ideia do museu, o primeiro espaço dedicado ao tema da morte e dos cemitérios no Brasil, surgiu em 2010 para abrigar o acervo da família Haas de Blumenau, cidade da região do Vale do Itajaí em Santa Catarina. Uma família de descendentes de imigrantes alemães, instalada na colônia de Ibirama, em Santa Catarina em 1904, que chegou com o patriarca Anton Haas, sua esposa Monika e seus filhos. Os Haas atuam há 100 anos no mercado funerário e reuniram um significativo conjunto de objetos e documentos sobre sua trajetória.

Desde 2007, eu vinha realizando inventários de cemitérios em Santa Catarina, dedicando-me, principalmente, a compreender as questões relacionadas à preservação do patrimônio funerário. Eu já ouvira falar do acervo, mas quando ministrava um curso sobre inventariamento funerário na Universidade Regional de Blumenau (FURB), recebi o convite da família para conhecer o local que o abrigava.

Ainda lembro desse momento como um dos mais instigantes de minha profissão. Eu já havia feito registro de mais de uma centena de cemitérios, mas diante daquela sala repleta de caixas, livros, revistas, objetos, ferramentas, partes tumulares e outros itens relacionados, especialmente, com a trajetória da empresa e da família, constatei que estava diante de um dos maiores acervos associados a uma empresa do setor funerário.

O acervo em questão foi reunido ao longo de décadas por Mathias, seu filho Guido e por Rolf, seu neto, com o apoio de outros familiares não especificados pela família. A partir do ato de guardar documentos impressos da empresa, máquinas e partes de obras tumulares, iniciado por Mathias, seus descendentes seguiram aumentando o conjunto com outros itens advindos da empresa, como também objetos da vida cotidiana e familiar, dentre eles, quadros, utensílios de cozinha, livros escolares. Após a morte de Mathias em 1963, eles mantiveram o acervo, especialmente um grande número de fotografias relacionadas com a empresa funerária e com o registro do dia a dia da família, como os livros de memória escritos por Mathias e por sua esposa. Na expansão física dos negócios, os Haas continuaram crescendo para outros espaços da propriedade da família, além daquela sala inicial, chegando a ocupar um galpão de proporções razoáveis.

A família não sabia ao certo como tratar o arquivo e passamos, então, a ponderar acerca do melhor modo de preservá-lo. É fato que já existia a preocupação com a memória da empresa, pois a família havia organizado uma exposição na cidade de Blumenau (SC), onde apresentou parte do acervo, por ocasião dos 90 anos da empresa, em 2008. Contudo, a possibilidade de criar uma instituição para sua preservação e divulgação não era consenso para os membros da família envolvidos, como Ronald e seu pai Rolf, dadas as dificuldades que previam para concretizá-la. Eu mal podia esperar o momento de torná-lo acessível ao público e, especialmente, aos pesquisadores, devido ao seu caráter singular, considerando o desconhecimento da existência de outros acervos de tal porte, ou de finalidades semelhantes. 
Igualmente, não tinha mais como ignorar cada detalhe, cada item que eu descobria naquela sala e imediatamente, comprometi-me em ajudá-los voluntariamente.

Naquele momento, eu havia recentemente iniciado o doutorado na Universidade Federal de Santa Catarina (UFSC), sob a orientação da profa. Dra. Maria Bernardete Ramos Flores. O tema da tese estava direcionado para o estudo dos cemitérios teutos brasileiros, a partir das obras tumulares, mas a visita motivou a mudança do tema, considerando a infinidade de fontes para minha pesquisa e a possibilidade de conjugar o doutorado com o trabalho no acervo. Gentilmente, minha orientadora concordou com a alteração do tema e iniciei o trabalho com a família. ${ }^{1}$

A tese, defendida em 2013 e intitulada "Aqui jaz uma morte: atitudes fúnebres na trajetória da empresa funerária da família Haas de Blumenau" permitiu refletir sobre as práticas mortuárias em diferentes momentos, e foi basilar para o trabalho com o Memorial, tornando possível conhecer uma parte significativa de sua trajetória, sobretudo, a da formação do arquivo, tendo sido imprescindível a coleta de depoimentos da família (Castro, 2013).

Inicialmente foi necessário conhecer a diversidade do acervo, que abrangia fotografias de túmulos e familiares, negativos de vidro, ferramentas, partes de construções tumulares, notas fiscais, máquinas, registros de empregados, material publicitário, projetos, malas, rádios, catálogos de túmulos, etc., o que apontou a necessidade de iniciar um trabalho por sua preservação. Por seu caráter singular, confirmou-se rapidamente que ele se enquadrava na área do patrimônio cultural funerário, segmento ainda pouco privilegiado nas políticas de proteção patrimonial, o que substantivava o seu valor. O patrimônio cultural funerário pode ser definido como:

conjunto de bens, materiais e imateriais, encontrados em locais de sepultamentos, acervos diversos, cemitérios e demais espaços e práticas relacionadas com a morte. Entende-se que este patrimônio incorpora além dos elementos mais diretamente relacionados aos cemitérios, também os lugares, atividades e ritos, dentre os quais estão os costumes de preparação do corpo e de velórios, tipos de cortejos e as celebrações pela passagem de datas, tais como, o Dia de Finados, missas de Sétimo Dia, cultos em lugares de morte dos conhecidos "santos populares", acervos pessoais e de empresas do ramo funerário, etc. O conjunto é bastante amplo e diverso e em nosso país comporta uma série de ricas relações das mais variadas origens que formam as práticas e crenças funerárias brasileiras (Castro, 2017, p. 5).

Primeiramente, munida de muitas fotos e anotações, passei a analisar o conjunto e de todos os itens chamou-me a atenção, especialmente, o diário do fundador, onde ele relatara a

1 Registro aqui meu agradecimento especial à Profa. Dra. Maria Bernardete Ramos Flores, minha orientadora de doutorado, por todo apoio às minhas pesquisas sobre os cemitérios. Sem sua generosidade e competência, o trabalho com o Memorial não teria sido possível. Aproveito também para destacar o papel fundamental da Associação Brasileira de Estudos Cemiteriais (ABEC), da qual faço parte e sou membro fundadora, na trajetória de meus trabalhos com o patrimônio cultural funerário. A convivência e a troca de experiências com os "cemiteriais" foram essenciais para a criação e fundamentação teórica dos estudos realizados ao longo do processo de criação do Memorial. Agradeço ainda ao amigo Anderson Felisberto Dias pelo apoio na leitura deste artigo. 
trajetória da família e da empresa, o que foi imprescindível para o entendimento do caráter da coleção que ele iniciara.

Além do "diário" escrito em alemão, que é mais um livro de memórias, Mathias Haas deixou outros escritos, como pequenas biografias e relatos. Também Rosa Johanna Haas, esposa de Mathias, escreveu suas memórias, e foi possível perceber que todos os escritos pessoais sinalizavam para a preocupação com a história familiar e da empresa, o que podia ser igualmente comprovado pelo número de itens guardados na propriedade da família.

Abaixo, na figura 1, podemos observar Mathias e Rosa Haas, sentados ao centro, cercados pelos filhos. Dela não se sabe quem foi o fotógrafo, contudo, sabe-se que o próprio Mathias foi o autor de muitas delas, que estão no acervo. Como esta fotografia, outras que retratam a família fazem parte do conjunto fotográfico dos arquivos formados por álbuns, fotos avulsas ou mesmo escritos pessoais de Mathias.

Figura 1 - Mathias, a esposa Rosa e filhos, 1939

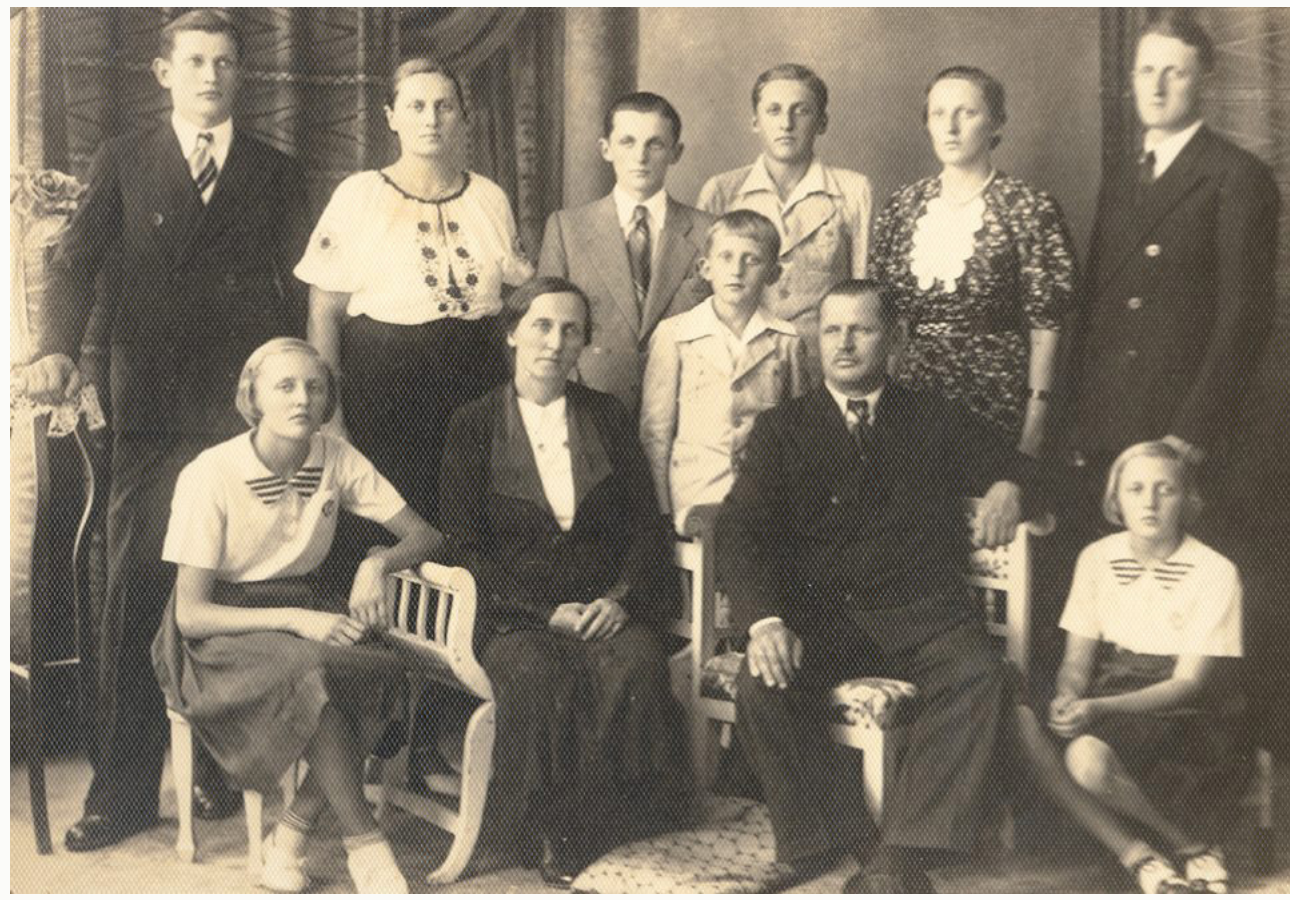

Fonte: Acervo do Memorial Funerário Mathias Haas

Mathias costumava narrar suas memórias com o auxílio de fotografias e legendas, como no caso do "Gedenkbuch und werdegang von Marmoraria Haas - Livro de Memórias e Trajetória da Marmoraria Haas", escrito perto de completar seus 50 anos, em fins da década de 1930. Na escrita destes "diários", percebe-se a intencionalidade de deixar suas impressões sobre a vida, e de construir uma trajetória de sua empresa e família. Para a historiadora Maria Teresa Ramos Cunha (2007, p. 54), tais escritos autobiográficos são "representações de um outro tempo, elevando a significados/produzindo sentidos à ordem do existente" e os diários, inclusive o de Rosa Haas, deve ser entendido neste contexto. 


\section{A família Haas e a trajetória da empresa}

Parte da memória da família está registrada nos escritos de Mathias, especialmente, em seus diários. Ele conta em seus textos que emigrara para o Brasil em 1904, e fixara residência na recém-criada colônia de Ibirama, junto com seus pais e irmãos. Inicialmente, ele trabalhou como agricultor e no serviço de fretes e, depois, junto com seu pai Anton Haas, começou a fabricar pedras de amolar, aproveitando a presença de arenito em sua propriedade e o conhecimento como escultor. Nos primeiros anos de seu trabalho como fabricante de pedras de amolar, Mathias recebeu a encomenda de uma lápide destinada ao sepultamento de uma criança. Ela foi a primeira de muitas outras encomendas de pedras tumulares e, de acordo com Mathias, acabou direcionando os negócios para a fabricação de lápides, iniciando assim a Marmoraria Haas.

A partir da encomenda da lápide, ocorrida por volta de 1911, a empresa da família Haas direcionou seu negócio ao mercado funerário. Mathias e seu pai eram escultores, com destaque para o próprio Mathias, que esculpia na pedra túmulos e ornamentos funerários. Na Figura 2, ele está em sua marmoraria, junto aos produtos em mostruário. O seu ofício de marmorista encontrou seu auge, no Brasil, entre fins do século XIX e começo do XX. O conjunto mais expressivo desta categoria de arte era, principalmente, voltado a atender as grandes demandas dos cemitérios e de obras citadinas, muitas delas "construções ecléticas que, então, foram surgindo na Europa e no Brasil" (Borges, 2002, p. 53).

Figura 2 - Mathias Haas e os produtos de sua Marmoraria

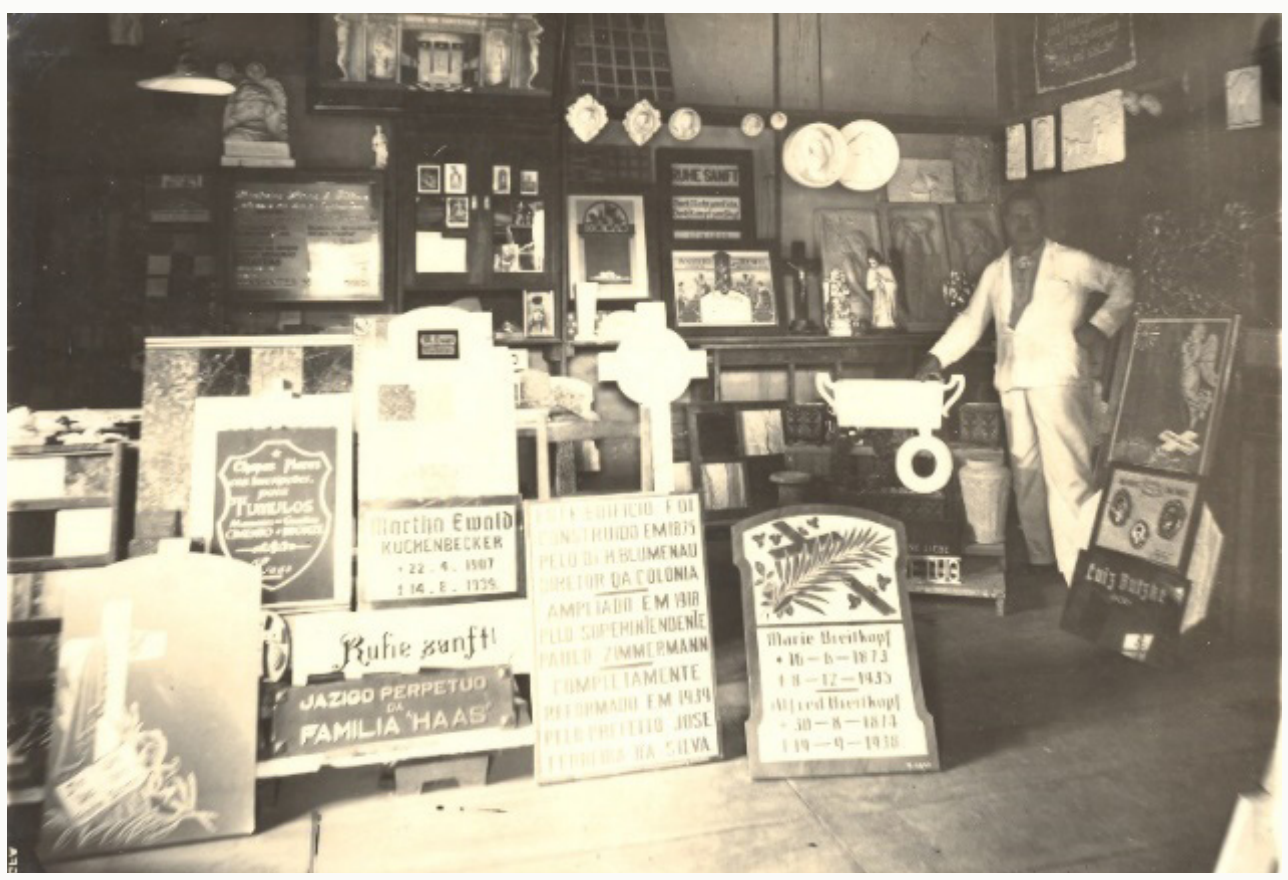

Fonte: Acervo do Memorial Funerário Mathias Haas 
A empresa, cuja administração sempre esteve a cargo de membros da família, necessitou rever seus produtos, ao longo dos seus 100 anos de existência, para conciliar mudanças nos ritos fúnebres e a entrada de novidades no mercado funerário. O seu fundador seguiu à frente da empresa até fins da década de 1940, quando assumiu seu filho, Guido Haas. Este, tendo recebido a marmoraria do pai, manteve-se no mercado investindo em máquinas para acompanhar as transformações no mercado funerário, como no caso da lustração de granitos, uma novidade introduzida no sul do Brasil pela marmoraria, além de direcionar a produção para a fabricação em série de obras em granito e granitina. Além de atender ao mercado funerário, a empresa também fabricava e comercializava itens para a arquitetura civil, como monumentos, escadas, revestimentos de piso, pias, entre outros.

Em 1967, outro Haas assume os negócios. É a vez de Guido passar a empresa para seu filho Rolf, que desativou a marmoraria e fez investimentos no setor de funerárias. Ele seguiu no comando até fins da década de 1990, quando começou a dividir a administração com seu filho Ronald. Ao longo das gerações, os Haas mantiveram o olhar atento às mudanças do mercado funerário e, assim, acabaram por empreender em diferentes áreas do setor, o que pode explicar a pluralidade de seu acervo. Começando como marmoraria, eles seguiram como funerária, depois como fábrica de caixões, e atualmente com a venda de planos funerários e a realização de cuidados com o corpo morto, como a tanatopraxia. ${ }^{2}$ Adaptando-se, conseguiram longevidade e estão prestes a completar seu centenário de atuação no mercado.

\section{A implantação do Memorial}

Em 2011, junto com Ronald Haas, filho de Rolf Haas, parti em busca de apoiadores. Uma das primeiras e importantes parcerias do projeto foi com o Museu Victor Meirelles, de Florianópolis (SC). ${ }^{3}$ Eu já conhecia o trabalho do museu, no qual tive a oportunidade de realizar cursos na área museológica, e ali conseguimos o apoio da equipe para avaliar e empreender as primeiras ações.

A gerência do Victor Meirelles disponibilizou, de seu quadro de funcionários, o museólogo Rafael Muniz, que foi de forma voluntária à cidade de Blumenau. Em sua primeira visita confirmou o valor do arquivo, por sua variedade e bom estado de conservação dos objetos, materiais impressos, fotografias e escritos pessoais. Ele propôs de imediato a sua organização preliminar, com a separação por tipos de suporte, conjuntamente com a colocação de mantas de proteção nas prateleiras metálicas e higienização preliminar, ação que foi realizada em setembro de 2011, com um grupo de voluntários de Blumenau e Florianópolis. ${ }^{4}$

Neste período iniciamos o estudo para a contratação de um funcionário para dar

2 A tanatopraxia pode ser definida como o "conjunto de práticas, fundamentadas em métodos e técnicas próprios da especialidade, conducentes à higienização, conservação, embalsamamento, reconstrução, restauração e cuidado estético de cadáveres, de acordo com as normas estabelecidas e respeitando os diferentes preceitos religiosos requeridos" (Anônimo, 2017).

3 Para mais informações sobre o Museu Victor Meirelles, ver <http://museuvictormeirelles.museus.gov.br/>.

4 Agradeço à Julia Massucheti Tomasi, Maria Helena Moratelli e Rachel Brambilla que foram voluntárias nesta ação. 
início à digitalização das fotografias. O conjunto guardado pela família em álbuns e, também, em unidades avulsas impressionava pela variedade temática. Decidimos iniciar o processo de digitalização e melhoria de sua guarda visando, principalmente, sua divulgação por meio de um site. A intenção era criar um museu virtual para buscar apoiadores para o projeto e dar acesso ao acervo para pesquisadores e público em geral, primeiramente, no ambiente web.

Figura 3 - Amostra do acervo fotográfico do Memorial
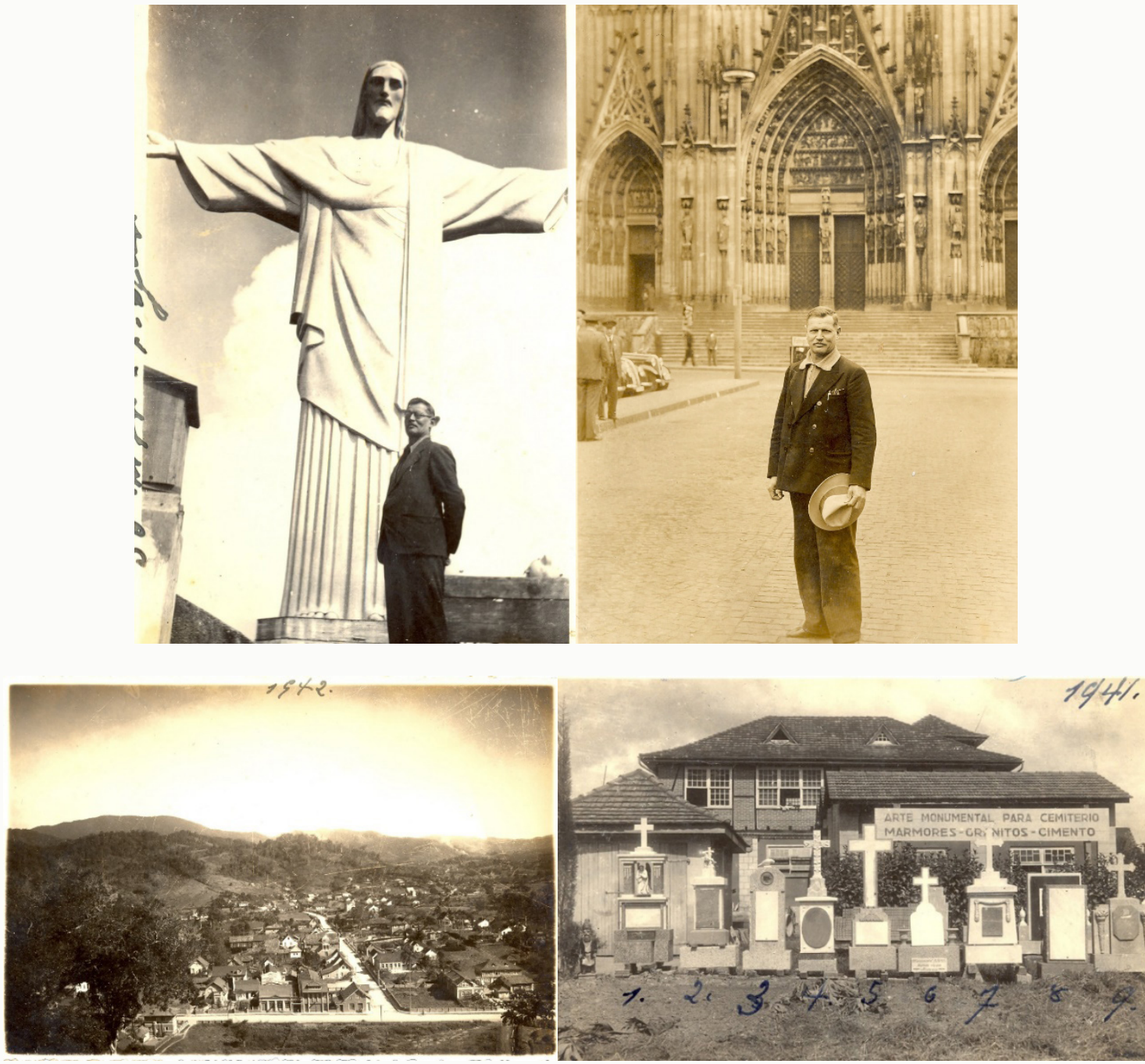

Fonte: Acervo do Memorial Funerário Mathias Haas

Para auxiliar o trabalho voltado às fotografias, o museu Victor Meirelles também disponibilizou a especialista em conservação e documentação fotográfica, Ana Viegas, que visitou o acervo em 2013, e propôs ações para sua preservação, como a compra de armários e formato mais adequado de guarda das fotografias, com a indicação de tipos de papeis específicos para seu acondicionamento, entre outras. O conjunto fotográfico do memorial é formado por temas variados e possui registros dos primeiros anos da família em Ibirama, a partir de 1904, como também de passeios, viagens, enchentes do Vale do Itajaí, cemitérios, 
obras feitas pela marmoraria, modelos tumulares, dentre outros, como consta na Figura 3.

Ainda em 2013, por indicação dos profissionais do museu, a museóloga Renata Cardozo Padilha passou a compor a equipe de trabalho, o que permitiu principiar a organização do inventário e demais etapas necessárias para a criação efetiva do museu. Naquele momento, já tendo iniciado algumas ações, Rolf Haas, neto de Mathias, concordou efetivamente com o projeto, confiando em nosso trabalho. Percebemos então que era preciso pensar, primeiramente, qual modelo de instituição seria mais adequado para abrigar o acervo, museu ou memorial, bem como sua missão. Também urgia estabelecer o modelo de inventário, tipos de coleções, primeiras ações de salvaguarda, dentre outros, que foram possíveis, a partir do ingresso da museóloga na equipe.

Com relação ao formato da instituição, entendemos que há uma diferença entre Museu e Memorial. O historiador Jorge Barcelos, em "O memorial como instituição no sistema de museus: conceitos e práticas na busca de um conteúdo", faz a ressalva de que o memorial não pode ser indiscriminadamente chamado de museu, e destaca que: "suas semelhanças dão-se apenas em sua forma, como aponta os Estatutos do ICOM para os museus em geral" (Barcelos, 1999, p. 5). Contudo, optamos pelo formato de Memorial, por questões administrativas e destacamos que sua função é análoga à de uma instituição museológica, que pode ser definida como "uma instituição colecionadora que organiza suas coleções conforme a natureza e a finalidade específica a que se destinam, e que tem por objetivo fundamental realizar ações de salvaguarda, pesquisa e comunicação de bens culturais materiais e imateriais que integram seu acervo" (Padilha, 2014, p.17).

Decidimos que o formato mais adequado às suas condições, bem como em relação às possibilidades da família seria o do Memorial. Com o nome de "Memorial Funerário Mathias Haas", em homenagem ao fundador da empresa e iniciador do acervo, a missão da instituição foi definida nestes termos: "Preservar, pesquisar e comunicar o acervo da família e empresa Haas e demais bens culturais relacionados ao patrimônio funerário, em seus aspectos materiais e imateriais e seus sentidos históricos, sociais, artísticos e culturais".

Igualmente importante, a concepção das coleções fez parte das primeiras definições e dada a diversidade de itens encontrados foram criadas seis coleções ${ }^{5}$, assim denominadas:

- Coleção I "Fotografia": para materiais como cópias fotográficas, negativos de vidro, diapositivo, negativos e slide;

- Coleção II "Documentos textuais": para catálogos, materiais de expedientes, notas fiscais, ofícios, orçamentos, projetos, livros, revistas, correspondências, material publicitários - materiais em suporte papel;

- Coleção III "Marmoraria": para materiais relacionados com o processo produtivo, como ferramentas, formas, maquinário, dentre outros;

5 "Uma coleção pode ser definida como um conjunto de objetos materiais ou imateriais (obras, artefatos, mentefatos, espécimes, documentos arquivísticos, testemunhos, etc.) que um indivíduo, ou um estabelecimento, se responsabilizou por reunir, classificar, selecionar e conservar em um contexto seguro e que, com frequência, é comunicada a um público mais ou menos vasto, seja esta uma coleção pública ou privada" (Desvallées e Mairesse, 2013, p. 33) 
- Coleção IV "Arquitetura tumular": para os produtos de fabricação, tais como túmulos, cabeceiras, ornamentos e suas partes;

- Coleção V "Miscelânea": para itens variados, como caixão artesanal e ornamentos;

- Coleção VI "Família Haas": para os escritos pessoais de Mathias e Rosa, cartas, fotografias familiares, correspondências e outros a serem classificados como pertencentes à coleção.

Com a definição do formato da instituição, missão, coleções e inventário, ${ }^{6}$ foi dada continuidade aos trabalhos, com a visita periódica ao acervo. A contratação de um estagiário pela empresa Haas permitiu o início do trabalho de digitalização da coleção fotográfica, bem como seu inventariamento. Contudo, a rotatividade de funcionários nos primeiros anos comprometeu o andamento do trabalho, que passou por várias revisões até ser finalizado.

As visitas permitiram realizar a avaliação das ações e a definição das etapas seguintes do trabalho. Terminado o inventariamento das fotografias, o mesmo seguiu para os demais itens do acervo. Nas avaliações, verificamos que o inventário não estava conforme o esperado, tendo sido encontrados erros de identificação e descrição. Importante destacar que, inicialmente, optamos por realizar o inventário, ao invés do arrolamento 7 para o conhecimento mais amplo das informações contidas nos documentos. Contudo, diante dos problemas identificados e com a troca de estagiário, decidimos reiniciar todo o processo, com o arrolamento para compreendermos a complexidade dos variados suportes e de conteúdo. ${ }^{8}$ A figura 4 apresenta objetos conhecidos, como chavetas, utilizadas em caixões para o fechamento da tampa, em processo de arrolamento.

6 Entende-se por inventário "o levantamento individualizado e completo dos bens de uma instituição ou pessoa. Nele consta o registro, identificação e classificação" (Yassuda, 2009, p. 24).

7 Entende-se por arrolamento "o ato por meio do qual se realiza a contagem de todos os objetos que fazem parte do museu, sendo criada uma lista numerada para controle e identificação geral do acervo museológico. Referese a um primeiro reconhecimento detalhado" (Padilha, 2014, p. 41).

8 Diante da indisponibilidade de recursos humanos e financeiros, decidiu-se pelo inventariamento, ao invés do arrolamento, apesar de entendermos que esta não seria a ordem mais adequada para a documentação do acervo. 
Figura 4 - Processo de arrolamento. Peças e ornamentos

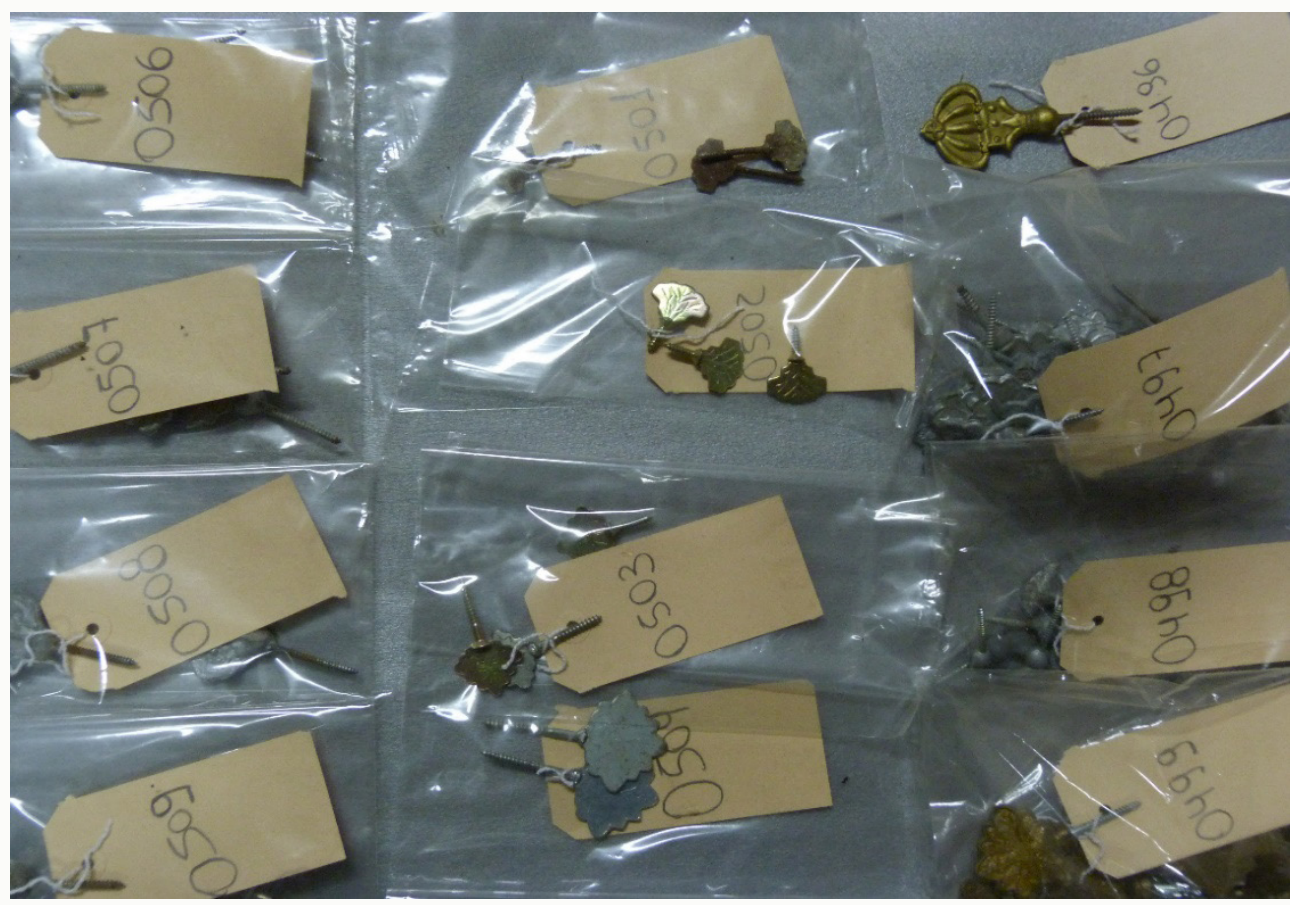

Fonte: Acervo do Memorial Funerário Mathias Haas

Em 2015, a equipe contava também com o apoio regular de mais um membro da família, Elke Haas Branco da Fonseca, irmã de Ronald, que passou a apoiar os trabalhos do estagiário Hugo Voigt e agilizar as demandas após cada reunião. Além de realizarmos o cadastro do Memorial no Portal Nacional de Museus, foi dada continuidade à proposta de divulgar o projeto na web, com o auxílio do profissional de web, Fábio Mayer, para desenvolver o site do Memorial. Nesse momento, a criação de uma logomarca foi essencial e, para tanto, buscou-se inspiração nos materiais de publicidade produzidos pela empresa, muitos deles feitos por seu fundador Mathias Haas. Outra fonte de inspiração foram os formatos tumulares produzidos pela Marmoraria Haas, e que são comumente encontrados nos cemitérios teuto brasileiros em Santa Catarina. Depois de alguns estudos, chegamos ao formato final, a seguir (ver Figura 5): 
Figura 5 - Logomarca do Memorial

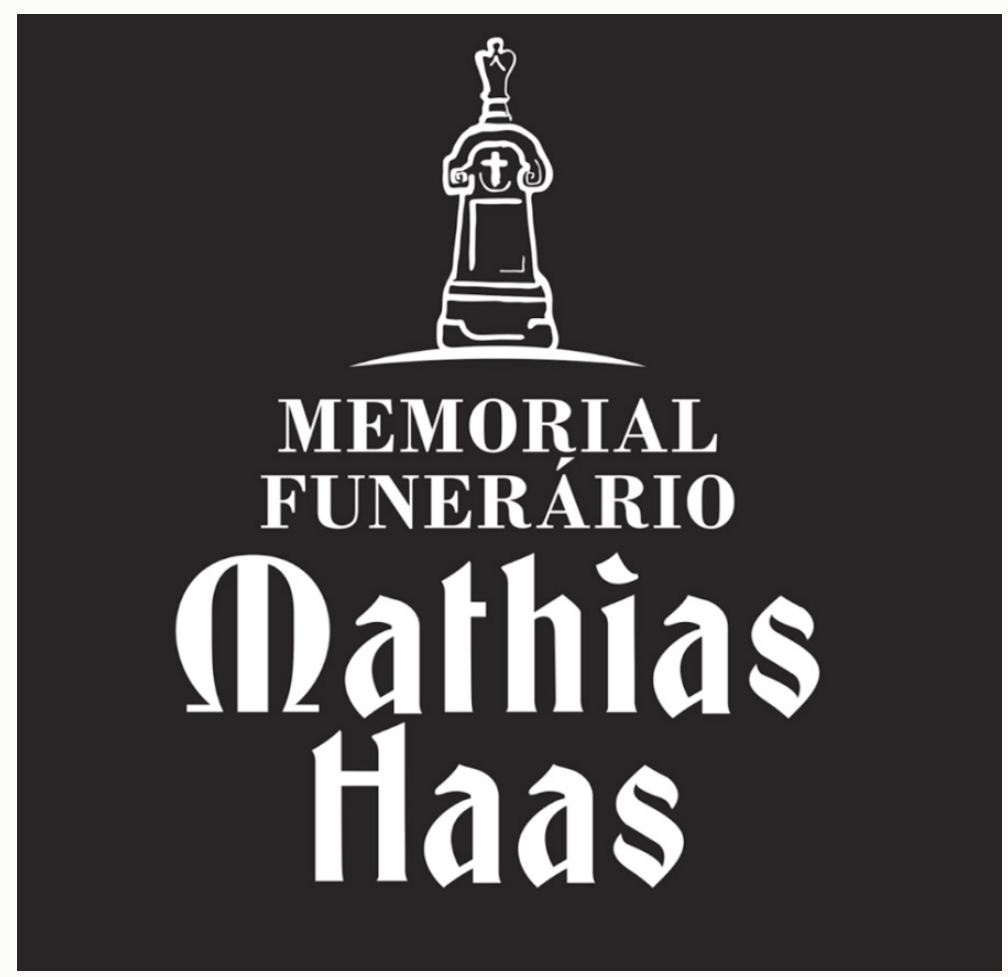

Fonte: Acervo do Memorial Funerário Mathias Haas

Igualmente importante, o espaço para abrigar o acervo era tema de reuniões com a família. O local considerado ideal era a construção feita por Mathias Haas, por volta de 1925 , que está junto da primeira sede da empresa em Blumenau. A casa foi a primeira residência da família na nova cidade, e está instalada no andar superior de um conjunto de salas onde funcionou a fábrica e a loja da Marmoraria Haas.

A construção é o símbolo da célere prosperidade da empresa, se considerarmos que apenas 10 anos após iniciar a pequena marmoraria em Ibirama, Mathias viu seu negócio crescer e decidiu seguir com a família para o centro mais dinâmico da época: a cidade de Blumenau. Junto com os filhos, Elza e Guido, ele iniciou a construção e anos mais tarde, seus demais filhos e a esposa seguiram para o novo lar. Na figura 6 a seguir, podemos observar parte do pátio da nova sede. Nele estão um menor aprendiz e um trabalhador não identificado, juntos ao monumento realizado pela Marmoraria Haas, por encomenda, para um colégio da cidade catarinense de Ascurra. A presença de menores trabalhadores neste segmento pode ser comprovada por meio do conjunto fotográfico do arquivo da empresa. Eles aparecem em situações de aprendizado e no cotidiano dos trabalhos realizados pela marmoraria. 
Figura 6 - Estátua de São Paulo feita para o Colégio São Paulo de Ascurra (SC), 1932

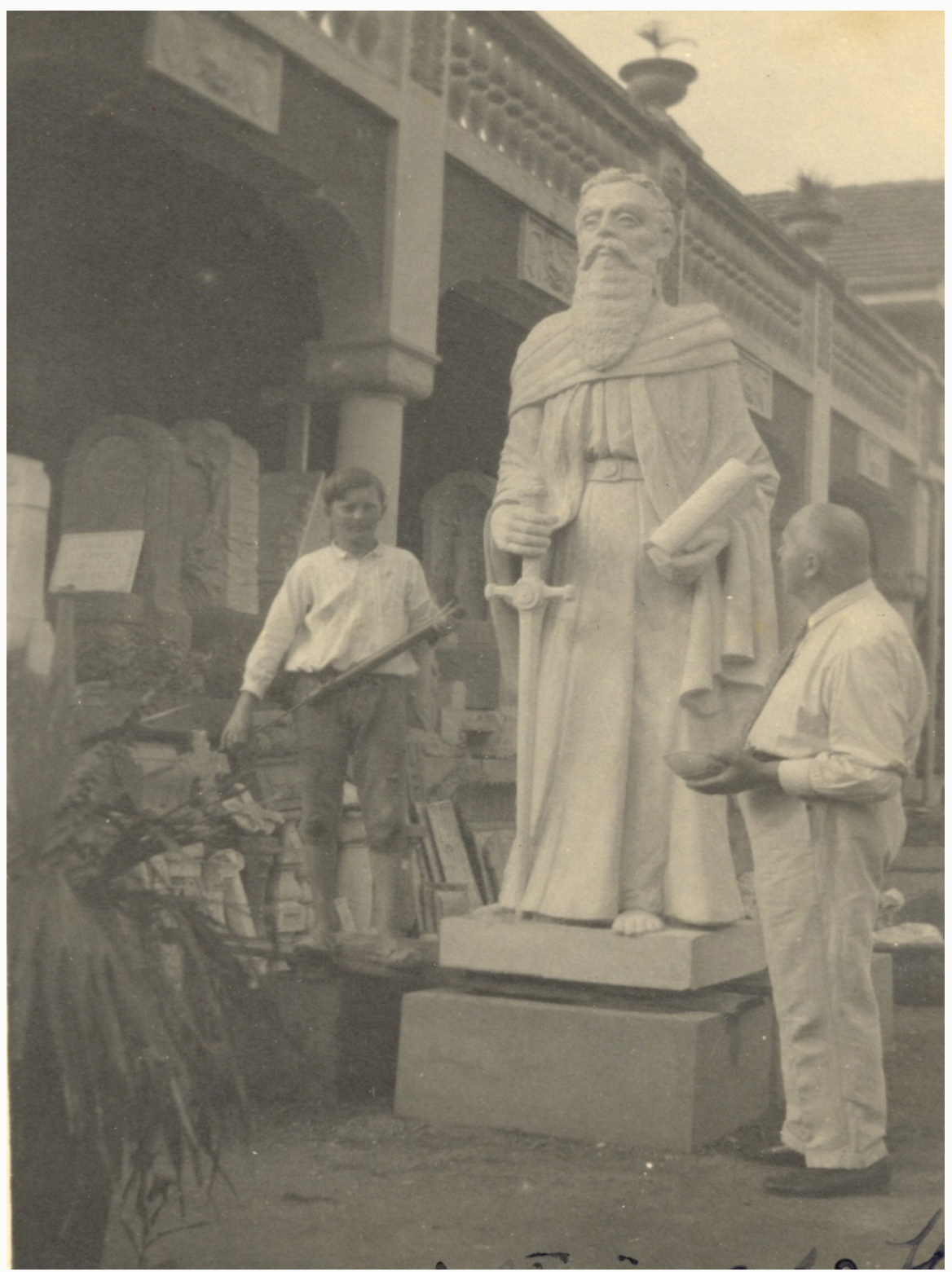

Fonte: Acervo do Memorial Funerário Mathias Haas

Na sede da rua São Paulo ainda funciona parte da empresa. Contudo, o estado de conservação da antiga residência e os investimentos necessários para sua adequação impossibilitaram seu uso. Ronald Haas sugeriu outra propriedade, que havia pertencido aos avós maternos de Ronald e Elke, adequada ao objetivo. Igualmente, como ocorreu ao conhecer o acervo, a primeira visita à casa que abrigaria o Memorial (Figura 7) surpreendeu pelo estado de conservação: ela estava intacta desde o falecimento dos avós, tendo sido mantida a disposição dos móveis e itens utilizados por seus antigos moradores. Confesso que custou-me alterar a configuração do imóvel para iniciar os trabalhos de adequação para o Memorial. Nesse sentido, de imediato sugeri que alguns de seus cômodos, como o hall de entrada e o banheiro, fossem mantidos os mais próximos da forma deixada pelos antigos habitantes, mantendo móveis e detalhes decorativos como parte do Memorial, a fim de contar um pouco da trajetória da casa. 
Além disso, solicitei que fossem feitos registros fotográficos dos ambientes e dos objetos, para guardar as informações sobre a casa e seu uso, como forma de documentar o processo de reformulação do espaço para abrir o acervo.

Figura 7- Casa que abriga o Memorial Funerário Mathias Haas

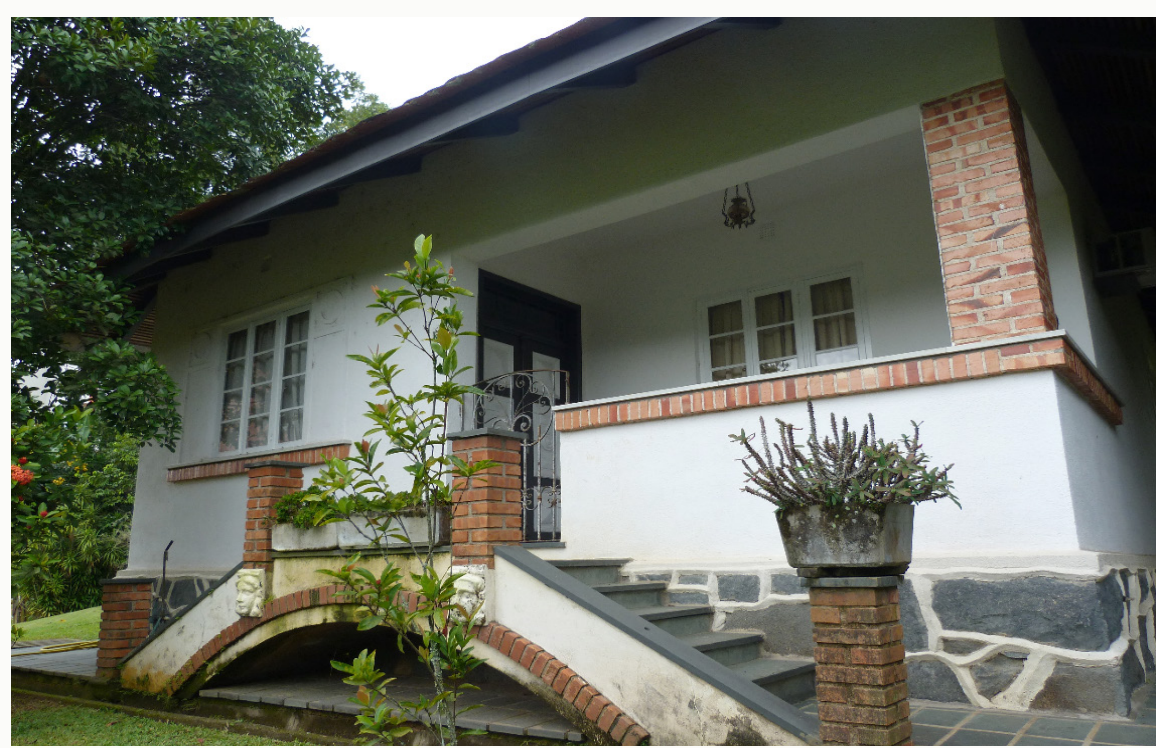

Fonte: Acervo do Memorial Funerário Mathias Haas

Um dos primeiros trabalhos na sede do Memorial foi a transferência de parte do acervo para o local escolhido para abrigar a reserva técnica. A sala da reserva técnica foi adequada com iluminação, cortinas, armários, aparelhos para controle térmico e prateleiras para dinamizar o arrolamento. Além dos itens que foram colocados na sala, também na propriedade da família havia outros itens, que seriam incorporados ao Memorial.

Figura 8 - Acervo em processo de arrolamento

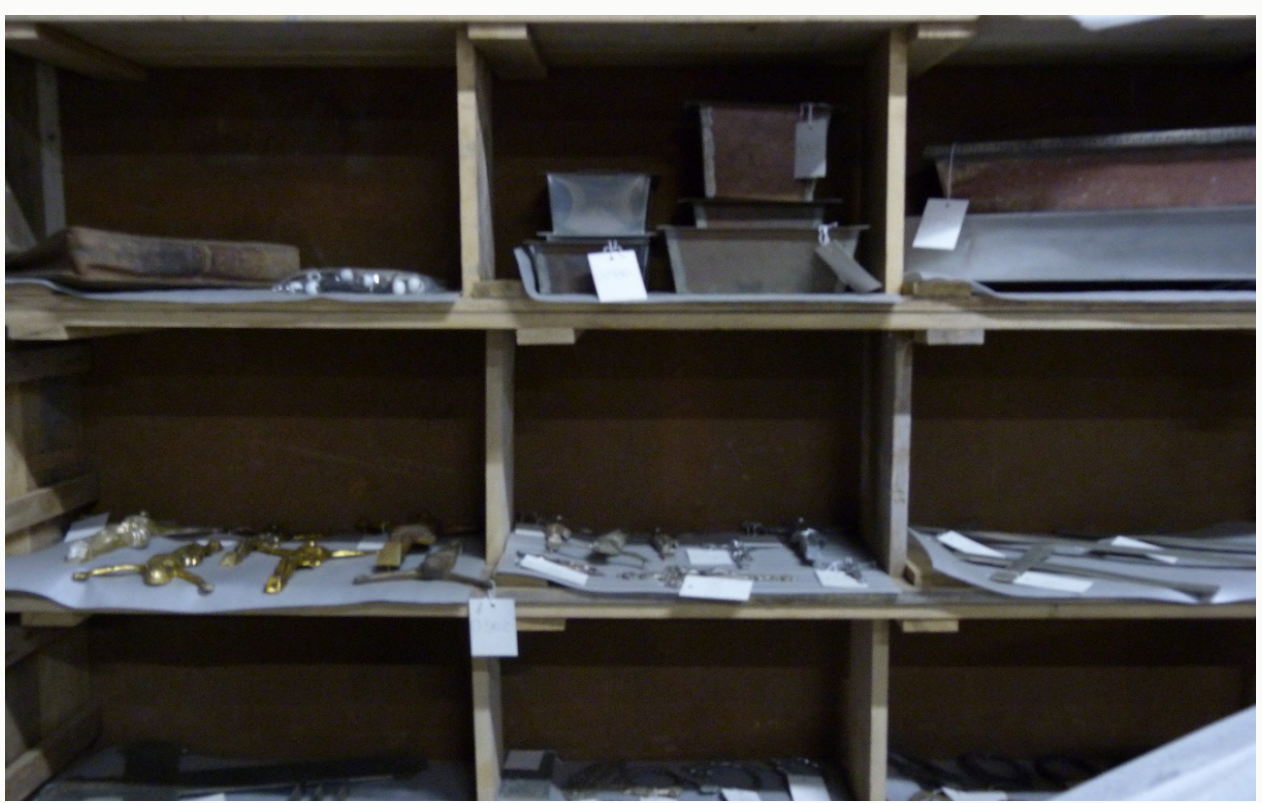

Fonte: Acervo do Memorial Funerário Mathias Haas 
Em uma das visitas realizamos a seleção dos demais objetos que a família guardara em um depósito, procedendo a separação dos tipos encontrados, conforme pode ser visto nas imagens 8 e 9 . Foram encontradas muitas peças produzidas pela marmoraria, algumas relativas ao período do funcionamento da fábrica de caixões, na década de 1980. Durante a gestão de Rolf Haas, pai de Ronald, a empresa arrendou uma funerária e abriu a fábrica que, apesar do pouco tempo de operação, resultou em um acervo que impressiona pela quantidade e variedade. Foi preciso realizar uma seleção, dada a quantidade de peças e, principalmente, de pequenos detalhes de ornamentos guardados após o fim da marmoraria e da fábrica de caixões, como tecidos e papeis usados para a confecção de caixões, letras para fabricação de lápides, suportes de urnas, dentre outros.

Figura 9 - Trabalho de organização para seleção

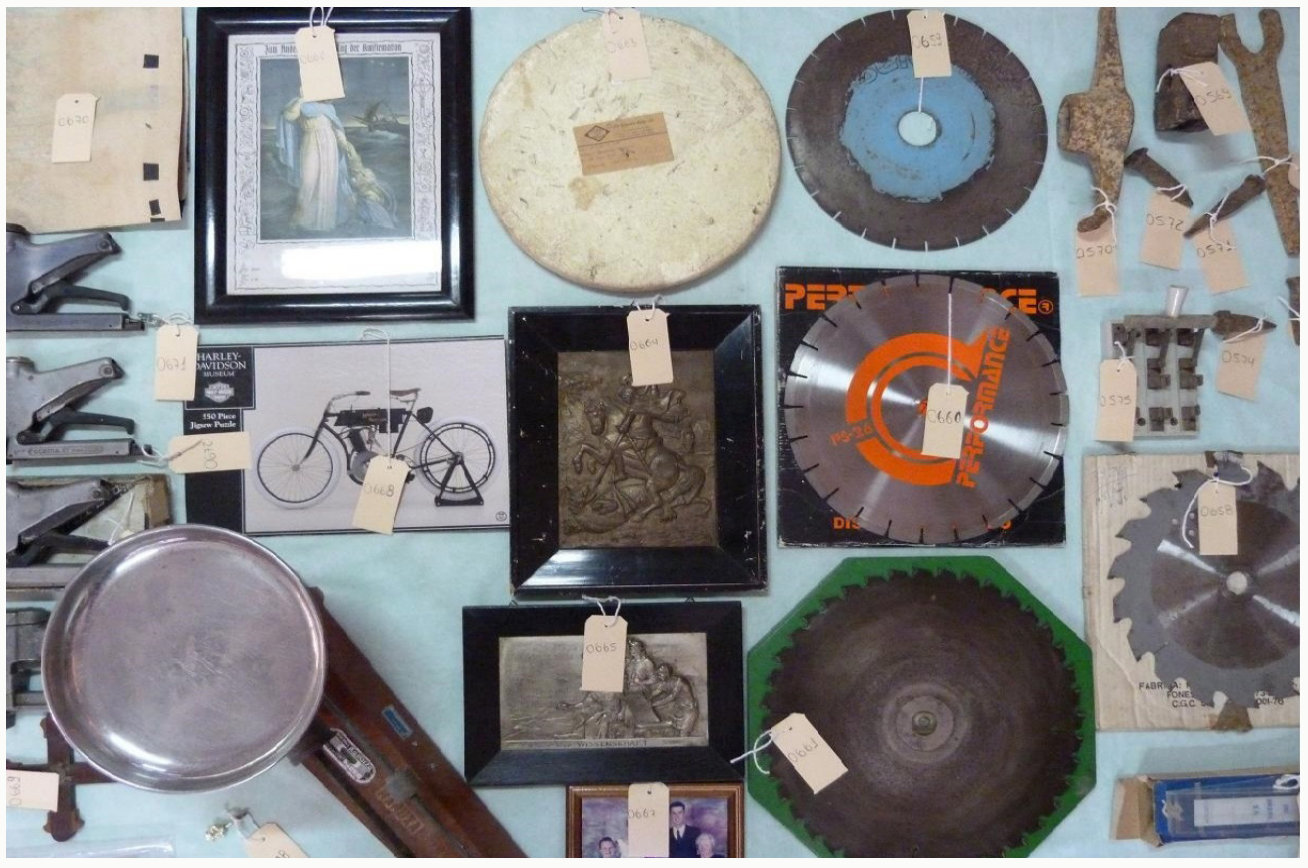

Fonte: Acervo do Memorial Funerário Mathias Haas

Além desses objetos, a família guarda um conjunto de formas e partes tumulares que estão em sua propriedade, em um galpão e na parte exterior, sob um telhado, protegidas do sol e da chuva. Contudo, dado o volume e o grande porte da maioria delas, requerem um estudo, para melhorar as condições de acondicionamento e a definição da maneira mais adequada de inclusão no acervo do memorial. De imediato, serão incorporadas algumas dessas peças de maior porte, como máquinas e partes de túmulos, a fim de integrarem a exposição do museu. 
Figura 10 - Na parte superior, identificação usada nos túmulos fabricados pela Haas e livro do acervo do Memorial. Embaixo, parte de epitáfios em alemão (Ruhe sanft: "Descanse em Paz")
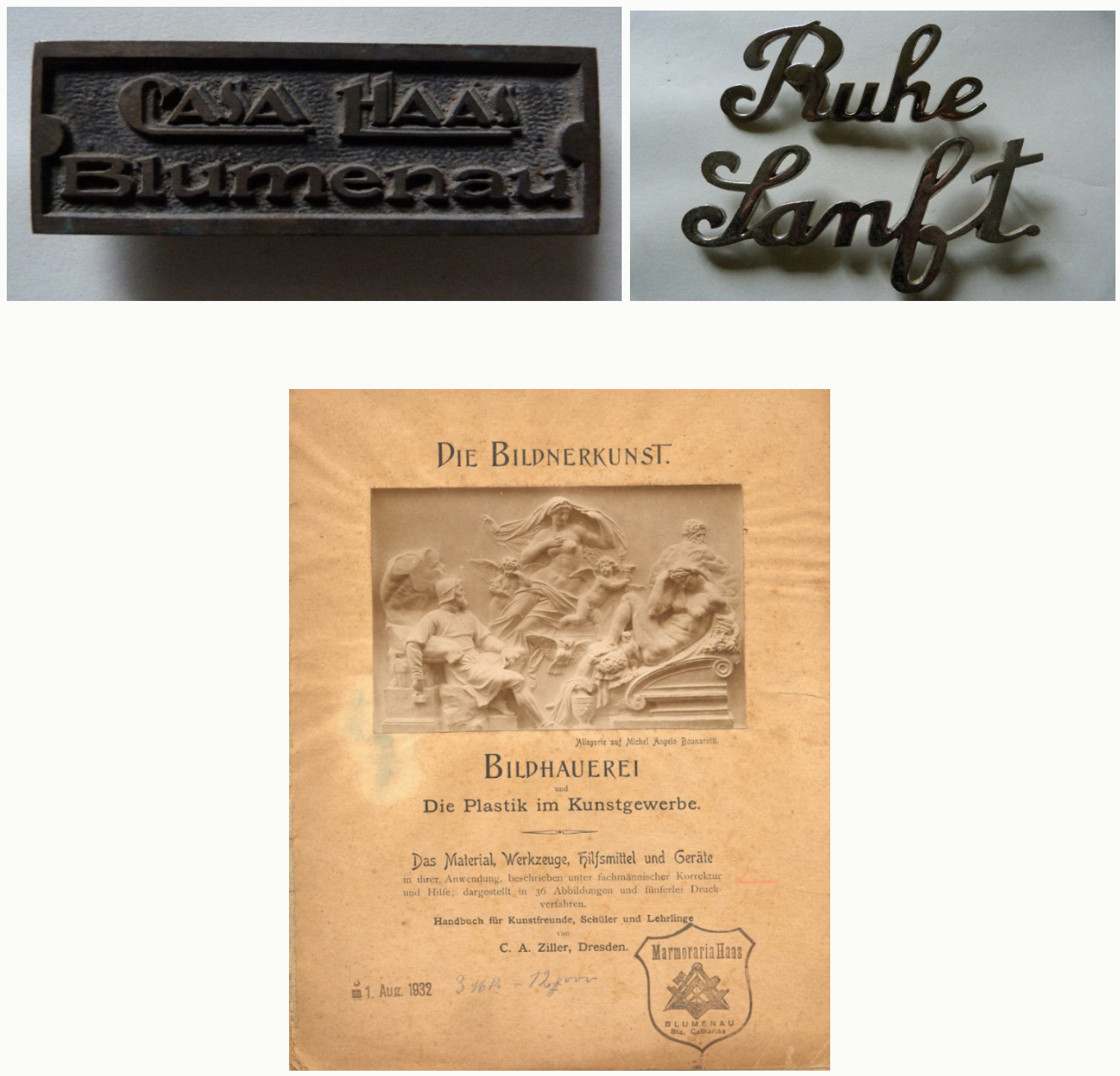

Fonte: Acervo do Memorial Funerário Mathias Haas

Em 2016 começamos a pensar sobre as etapas para inauguração do Memorial, prevista para julho de 2017. Contando com o apoio do atual estagiário Claudemar Costa Müller, os trabalhos de arrolamento foram desenvolvidos com mais agilidade, o que permitiu a seleção de objetos e o conhecimento de uma parte maior do conjunto, essencial para a criação da expografia e outras ações do Memorial.

No momento, a expografia do Memorial está em fase de finalização, com o apoio adicional de Igor Soares Amorim e do designer Fernando Azevedo. O processo de criação da primeira exposição tem sido profícuo em debates e em reflexões sobre narrativas, propostas e sentidos. A primeira exposição começou a ser elaborada em 2016, contudo nas discussões sobre o formato e a visão do Memorial, já travávamos debates sobre a proposta de suas exposições e sempre consideramos importante propor reflexões sobre a finitude humana, principalmente, sobre o lugar da morte, em especial, dos cemitérios em nossa sociedade na 
contemporaneidade, por meio da atuação e da experiência da família e de seus colaboradores.

A questão referente à morte na contemporaneidade é entendida a partir de seu afastamento do cotidiano, com o deslocamento do moribundo para o hospital, e com a afirmação de uma arquitetura discreta nos cemitérios e de certo comedimento nas expressões de luto. Pode-se ainda acrescentar que, especialmente, o "século XX caracteriza-se pela cultura urbanizada que exilou a morte, mascarando-a. Não há discussão ou reflexão sobre o medo da morte e suas consequências. No passado, a despeito de todos os temores, esta se encontrava presente nos lares" (Almeida, 2007, p. 98).

Diante de mudanças fundamentais ocorridas, tanto no formato dos cemitérios como no ofício dos trabalhadores do setor, considerou-se importante trazer para esta primeira exposição uma reflexão sobre a morte na contemporaneidade, a partir da trajetória da empresa e, especialmente, das transformações vivenciadas nos ritos e no segmento funerário.

Ao longo dos anos foi possível perceber como a relação com o mercado funerário marcou significativamente as relações sociais e familiares dos Haas, sempre lembrados, no cotidiano de seu trabalho como os que "mexiam ou lidavam com os mortos". Tal situação também tocava seus funcionários, o que foi observado na convivência durante a realização deste trabalho, em depoimentos e conversas travadas com os colaboradores.

O acervo sobre a empresa e sobre a família diz respeito, principalmente, ao ofício da morte, ao trabalho de tratar do corpo morto, sepultar e construir túmulos. O motivo do empreendimento e da atuação da marmoraria, da funerária e da criação do atual Plano Boa Vida, um plano familiar de assistência ao funeral.

O conjunto permite refletir sobre a trajetória de um empreendimento que, apesar de estigmatizado na sociedade atual, por relacionar-se com a morte, com o tratamento dos mortos e com o cemitério, tem como marca o dinamismo desde a sua criação, por volta de 1911, sendo o ano de 1918, considerado o oficial pela família. A empresa continuou a expandir seu mercado ao longo de décadas, transmitindo seu trabalho no ramo funerário, de geração em geração. Tal como a empresa, igualmente o arquivo, iniciado pelo fundador Mathias Haas, seguiu crescendo com Guido, Rolf, Ronald e familiares. É fato que eles ainda continuam a acolher e guardar outros itens, que agora começam a ser doados por outros membros da família, descendentes de Mathias e Rosa, o que só deve aumentar com a inauguração do Memorial.

Apesar dos sete anos que se passaram desde o início do projeto e tendo inaugurado o Memorial há pouco tempo, ainda temos muito trabalho pela frente, neste que pode ser considerado o primeiro museu dedicado à morte e aos cemitérios no Brasil. Continuaremos com o inventariamento do acervo, que tem crescido com doações e novos acréscimos da família, com a ampliação do espaço museográfico do Memorial e a formação da biblioteca, que já conta com obras trazidas pela família da Alemanha, com destaque para catálogos de túmulos e revistas diversas.

O Memorial Funerário Mathias Haas é fruto de muito empenho e associativismo. Empenho da família que levou adiante a proposta, sem aporte financeiro de terceiros, apesar de termos concorrido sem sucesso em três editais culturais, paixão confessa minha, pela história 
da família que virou tese, e pelo tema dos cemitérios, ao qual dedico parte significativa de meus dias e da associação de bons companheiros de trabalho, que aqui foram citados. Sem eles, eu não passaria de uma louca apaixonada pelo tema, o que talvez ainda seja.

\section{Bibliografia}

ALMEIDA, Marcelina das Graças de. Morte, Cultura, Memória - Múltiplas Interseções: Uma interpretação acerca dos cemitérios oitocentistas situados nas cidades do Porto e Belo Horizonte. Tese (Doutorado em História), Programa em História Social da Cultura, Faculdade de Filosofia e Ciências Humanas, Universidade Federal de Minas Gerais, Belo Horizonte, 2007. 320 p. Disponível em: <http://hdl.handle.net/1843/VGRO-7BYFBK>. Acesso em: 25/11/2017.

ANÔNIMO. Tanatopraxia. In:

Dicionário Infopédia da Língua Portuguesa com Acordo Ortográfico. Porto: Porto Editora, 2017, s.p. Disponível em: <https://www.infopedia.pt/ dicionarios/lingua-portuguesa/tanatopraxia>. Acesso em: 25/11/2017.

BARCELLOS, Jorge. O memorial como instituição no sistema de museus. Conceitos e práticas na busca de um conteúdo. Versão modificada da palestra apresentada no Fórum Estadual de Museus. Porto Alegre, 1999. 10p. Disponível em: <www.memorial.mppr.mp.br/arquivos/File/ Barcellos.pdf>. Acesso em: 22/05/2017.

BORGES, Maria Elizia. Arte funerária no Brasil (1890-1930): ofício de marmoristas italianos em Ribeirão Preto. Belo Horizonte: Editora C/ Arte, 2002. 311p.

CASTRO, Elisiana Trilha. Aqui jaz uma morte: atitudes fúnebres na trajetória da empresa funerária da família Haas de Blumenau. Tese (Doutorado em História), Centro de Filosofia e Ciências Humanas, Programa de Pós-Graduação em História, Universidade Federal de Santa Catarina, Florianópolis, 2013. 399p. Disponível em: <https://repositorio.ufsc.br/ handle/123456789/107130>. Acesso em: 25/11/2017.

\section{Guia do Patrimônio Funerário Catarinense. Florianópolis: IOESC, 2017. 55p.}

CUNHA, Maria Teresa Ramos. Do Baú ao Arquivo: Escritas de si, escritas do outro. Patrimônio e Memória. Presidente Prudente, v. 3, n.1, p. 1-18, 2007. Disponível em: <http://pem.assis.unesp. br/index.php/pem/article/view/8/8>. Acesso em: 25/11/2017.

DESVALLÉES, André e MAIRESSE, François (Orgs.). Conceitos-chave de Museologia. São Paulo: Comitê Brasileiro do Conselho Internacional de Museus Conselho Internacional de Museus; Pinacoteca do Estado de São Paulo; Secretaria de Estado da Cultura, 2013. 100p. Disponível em: $<$ http://icom.museum/fileadmin/user_upload/pdf/Key_Concepts_of_Museology/ConceitosChavedeMuseologia_pt.pdf $>$. Acesso em: 25/11/2017.

PADILHA, Renata Cardozo. Documentação Museológica e Gestão de Acervo. Coleção Estudos Museológicos, v.2. Florianópolis: FCC, 2014. 74p.

YASSUDA, Sílvia Nathaly. Documentação museológica: uma reflexão sobre o tratamento descritivo do objeto no Museu Paulista. Dissertação (Mestrado em Ciência da Informação), Faculdade de Filosofia e Ciências, Universidade Estadual Paulista, Marília, 2009. 123p. Disponível 
em: <https://www.marilia.unesp.br/Home/Pos-Graduacao/Cienciadalnformacao/Dissertacoes/ yassuda_sn_me_mar.pdf>. Acesso em: 25/11/2017.

Recebido em: 02 de novembro de 2017.

Aprovado em: 15 de novembro de 2017. 